\title{
Pengenalan Perangkat Keselamatan Sarana Pelabuhan Moda Waterway Sungai Tallo Makassar
}

\author{
Taufiqur Rachman*, Juswan, Daeng Paroka, Achmad Yasir Baeda, Sabaruddin Rahman, Chairul \\ Paotonan, Hasdinar, Muhammad Zubair MA, Ashury, Firman Husain \\ Departemen Teknik Kelautan, Fakultas Teknik UNHAS \\ trachman@unhas.ac.id*
}

\begin{abstract}
Abstrak
Pengoperasian sebuah pelabuhan moda waterway harus memenuhi syarat adanya perangkat keselamatan yang memenuhi standar pelayanan sandar dan tambat secara layak dan aman bagi penumpang dan barang. Sarana pelabuhan dermaga 3 Lakkang yang melayani moda waterway Sungai Tallo dengan rute Kera-kera - Pulau Lakkang yang merupakan kawasan wisata sejarah ini tidak dilengkapi dengan perangkat keselamatan dan kondisi trestle dermaga 3 yang dibangun sejak tahun 2013 ini sudah mulai mengalami kerusakan. Hal ini mengakibatkan mutu pelayanan sandar dan tambat kurang aman ditinjau dari aspek keselamatan bongkar muat penumpang dan kendaraan roda dua. Sosialisasi kebutuhan perangkat keselamatan dan pemenuhan sarana pelabuhan yang layak dan aman secara mandiri perlu dilakukan dalam penerapan keselamatan sarana pelabuhan angkutan moda. Transfer pengetahuan melalui sosialisasi ini akan meningkatkan standar mutu layanan sandar dan tambat secara aman dan nyaman bagi penumpang dan barang angkutan moda waterway Sungai Tallo sesuai Peraturan Pemerintah Nomor 64 Tahun 2015 perubahan atas Peraturan Pemerintah 61 Tahun 2009 tentang kepelabuhanan. Sosialisasi dan perbaikan jembatan penghubung (trestle) dan geladak moda waterway kepada kelompok moda waterway ini dapat menambah keselamatan, keamanan, dan kenyamanan penumpang lokal dan pengunjung wisata Lakkang baik turis domestik maupun mancanegara dalam pelayaran dan proses bongkar dan muat waterway di dermaga 3 Lakkang. Respon positif diberikan oleh penumpang dan pemilik moda waterway. Mereka berharap bahwa kegiatan serupa yang memberi nuansa pengetahuan baru bagi kelompok moda waterway sebagai operator khususnya dan kepada khalayak warga Kelurahan Lakkang umumnya.
\end{abstract}

Kata Kunci: Moda Waterway; Sarana Pelabuhan; Keselamatan Jiwa.

\section{Pendahuluan}

Perkembangan moda transportasi air (waterway) telah beroperasi sejak lama di Kota Makassar. Transformasi moda transportasi air ini berawal dengan bentuk yang sederhana yakni rakit bambu (getek), perahu katinting, hingga katamaran, sesuai Gambar 1. Salah satu moda transportasi waterway yang perkembangannya cukup pesat adalah moda transportasi waterway Sungai Tallo dengan rute Lakkang-Kera-kera.

Lakkang, terletak dalam kawasan Kelurahan Lakkang Kecamatan Tallo dan sejak tahun 2011 ditetapkan sebagai Desa Wisata oleh Pemerintah Kota Makassar, yang menjadi salah satu destinasi wisata sejarah baru di Makassar dengan bunker Jepang sebagai daya tarik unggulannya. Lakkang juga merupakan kawasan penelitian terpadu serta daerah konservasi alam dan budaya. Sedangkan Kera-kera terletak di Dusun Kera-kera, suatu wilayah yang terletak di bagian barat Universitas Hasanuddin, Kelurahan Tamalanrea Indah di Kecamatan Tamalanrea. Moda waterway ini merupakan satu-satunya akses moda bagi warga Kelurahan Lakkang menuju ke bagian timur dan selatan Kota Makassar dengan menyusuri Sungai Tallo, guna berbelanja kebutuhan sehari-hari dengan mengangkut penumpang dan barang serta kendaraan motor. 
a

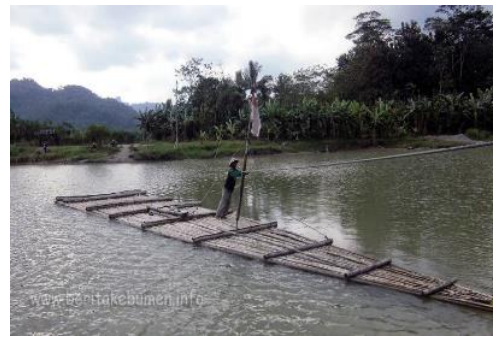

$\mathrm{b}$

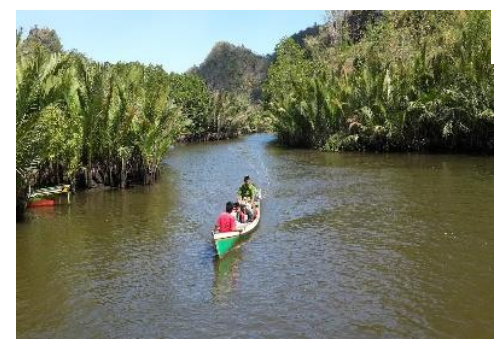

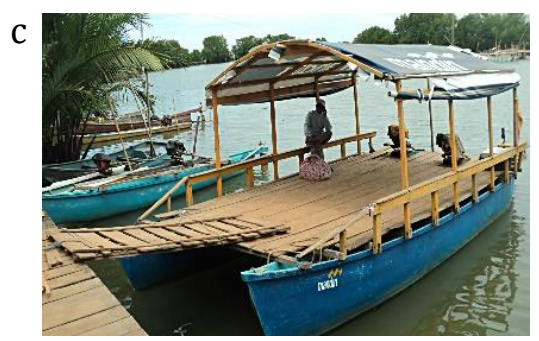

Gambar 1. Transformasi Moda Waterway Sungai Tallo Makassar

(a) Getek; (b) Perahu katinting; (c) Katamaran

Sumber: Dokumentasi survey (2017)

Pengoperasian moda transportasi waterway Sungai Tallo ini harus memenuhi syarat adanya perlengkapan keselamatan sarana pelabuhan di kedua ujung rute, Gambar 2. Salah satu sarana pelabuhan yang terpenting adalah dermaga, yakni tempat moda transportasi (kapal/perahu) ditambatkan dan dilakukan berbagai kegiatan bongkar muat barang dan penumpang dari dan ke atas kapal/perahu (Triatmodjo, 2008: 29). Sebuah dermaga harus memenuhi standar pelayanan sandar dan tambat secara layak dan aman bagi penumpang dan barang (PP No. 64, 2015; Permen RI No. PM 51, 2015). Oleh karena itu, pemilik moda waterway harus mengetahui kebutuhan perangkat keselamatan moda waterway-nya dalam menerapkan keselamatan angkutan moda dan pemenuhan sarana pelabuhan yang layak dan aman.

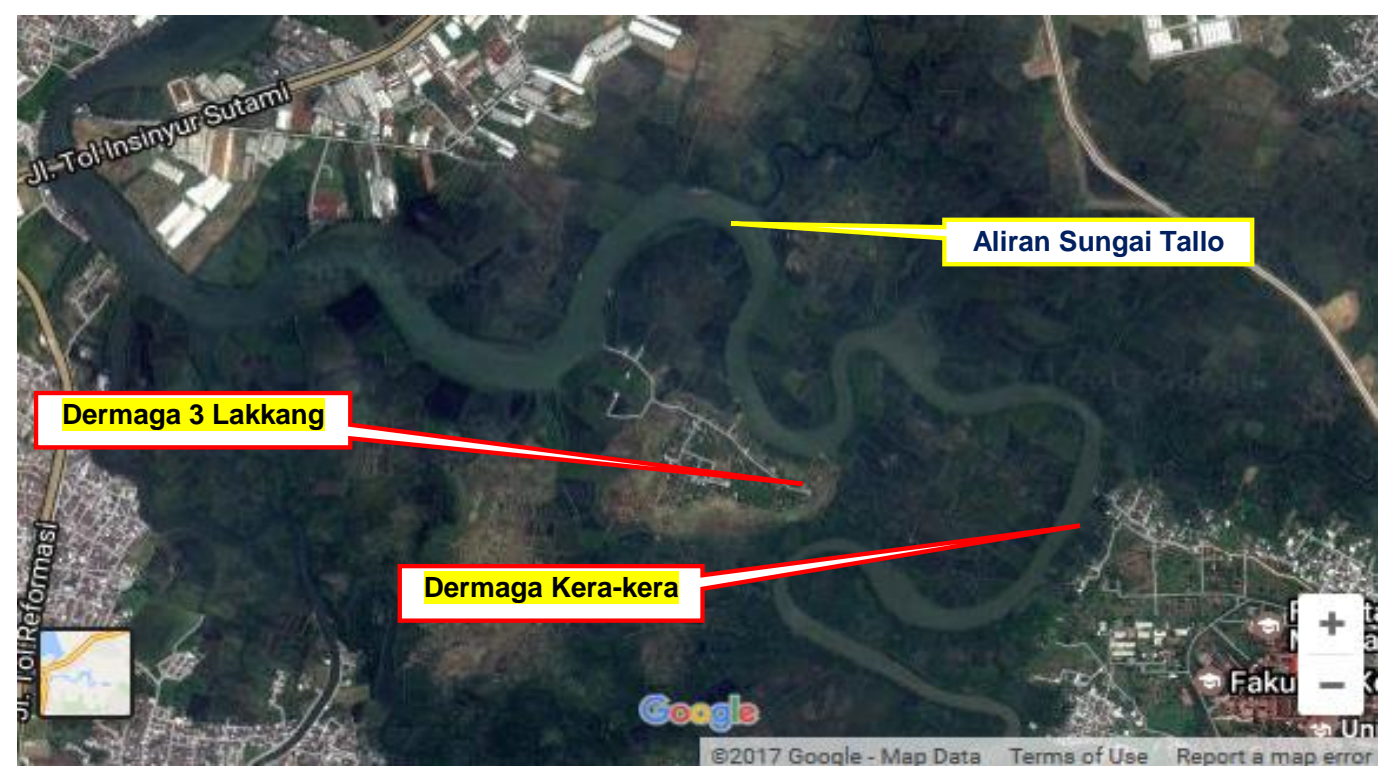

Gambar 2. Pengoperasian Moda Waterway Sungai Tallo antara Dermaga Kera-Kera dan Lakkang 
Pulau Lakkang memiliki fasilitas dermaga sebanyak 5 buah. Seluruh dermaga ini dibangun oleh instansi pemerintah dan swasta. Khusus kondisi dermaga 3 Lakkang yang dibangun tahun 2013 ini sudah mulai rusak di beberapa bagian konstruksinya sehingga dapat dikategorikan tidak layak memberikan pelayanan sandar dan tambat sesuai standar keselamatan, keamanan dan kenyamanan bagi penumpang dan barang.

Salah satu pemilik kelompok moda waterway Sungai Tallo telah menyampaikan keluhannya tentang proses bongkar muat penumpang di dermaga 3 Lakkang akibat kerusakan beberapa bagian konstruksinya, dengan kata lain mutu layanan sandar dan tambat bagi moda waterway ini kurang aman bagi penumpang terlebih lagi kendaraan roda dua. Kelompok moda waterway Sungai Tallo ini memohon dan bersedia menjadi mitra dalam proses transfer pengetahuan tentang pentingnya penerapan sarana pelabuhan yang layak dan aman dalam pengoperasiannya. Masalah yang mereka hadapi saat ini perasaan khawatir terjerembab dan jatuhnya para penumpang dan pengendara kendaraan roda dua yang melintasi trestle pada saat berlabuh di dermaga 3 Lakkang eksisting sehingga aktifitas bongkar muat ini tidak memberikan rasa aman dan nyaman bagi warga Kelurahan Lakkang, terlebih lagi bagi mutu layanan penumpang wisata domestik maupun wisata asing yang akan berwisata ke Pulau Lakkang.

Berdasarkan latar belakang di atas maka perlu diadakan sosialisasi pengenalan dan kebutuhan perangkat keselamatan sarana pelabuhan bagi kelompok pemilik moda waterway Sungai Tallo Makassar agar dapat melengkapi pemenuhan perangkat keselamatan sarana pelabuhan secara mandiri yang sesuai dengan mutu pelayanan sandar dan tambat secara aman dan nyaman bagi penumpang dan barang.

\section{Latar Belakang Teori}

\subsection{Penyelenggaraan Angkutan Sungai dan Danau}

Angkutan sungai dan danau adalah kegiatan angkutan dengan menggunakan kapal yang dilakukan di sungai, danau, waduk, rawa, banjir kanal, dan terusan untuk mengangkut penumpang dan/atau barang yang diselenggarakan oleh perusahaan angkutan sungai dan danau. Sesuai pasal 14 PP 82/1999 tentang Penyelenggaraan Angkutan Sungai dan KM 73/2004 (Keputusan Menteri No. 73 Tahun 2004 tentang Penyelenggaraan Angkutan Sungai dan Juknis Direktorat Perhubungan Darat), penyelenggaraan angkutan sungai dan danau dapat dilakukan oleh a/. Perusahaan angkutan sungai dan danau; b/. Dengan menggunakan kapal berbendera Indonesia yang memenuhi persyaratan kelaikan dan diperuntukkan bagi angkutan sungai dan danau dan di wilayah operasi perairan daratan. Wilayah operasi angkutan sungai dan danau meliputi sungai, danau, waduk, rawa, banjir kanal dan terusan. Meskipun moda waterway Sungai Tallo merupakan moda transportasi yang dimiliki dan dikelola secara perorangan/pribadi yang bertempat tinggal di Pulau Lakkang, namun karena menyangkut pemenuhan persyaratan kelayakan bagi keselamatan penumpang dan barang angkutan sungai maka moda waterway tetap harus memenuhi persyaratan kedua peraturan di atas.

UU No. 17 Tahun 2008 menyebutkan bahwa dalam penyelenggaraan angkutan sungai dan danau harus memperhatikian keselamatan dan keamanan pelayaran meliputi keselamatan dan keamanan angkutan di 1/. Perairan; 2/. Pelabuhan; dan 3/. Perlindungan lingkungan maritim. Lebih lanjut, penyelenggaraan angkutan sungai dan danau juga mengadopsi standar internasional seperti International Maritime Organization (IMO), dengan melakukan penyesuaian dengan kondisi di Indonesia. 
Pengertian keselamatan dan keamanan angkutan perairan yaitu kondisi terpenuhinya persyaratan: a/ Kelaiklautan moda transportasi (kapal) yang ditunjukkan melalui sertifikat dan surat kapal, dan b/. Kenavigasian (Pasal 117, 118 UU 17/2008). Sedangkan pengertian keselamatan dan keamanan pelabuhan yaitu kondisi terpenuhinya manajemen keselamatan dan sistem pengamanan fasilitas pelabuhan yang meliputi: a/. Prosedur pengamanan fasilitas pelabuhan; b/. Sarana dan prasarana pengamanan pelabuhan; c/. Sistem komunikasi; dan d/. Personil pengaman (Pasal 121 UU 17/2008).

Kapal-kapal yang digunakan pada perairan sungai dan danau dapat dikelompokkan menjadi 2 yaitu kapal yang hanya beroperasi di perairan sungai saja dengan ciri utamanya freebord yang rendah karena tidak akan menghadapi perairan yang berombak, dan kapal yang beroperasi di perairan sungai dan laut yang freeboard-nya lebih tinggi. Kapal-kapal yang melalui perairan sungai dikelompokkan kepada kapal yang berlayar hanya di perairan sungai saja dan kapal-kapal yang berlayar di laut dan masuk ke perairan sungai, biasanya berupa kapal petikemas, kapal barang umum, dan kapal penyeberangan.

Salah satu tipe kapal perairan sungai dan danau adalah kapal penumpang yang terdiri atas: a/. Bus air; b/. Taxi air; c/. Getek/klotok; d/. Kapal barang; e/. Tongkang; f/. Tongkang bermesin; g/. Kapal barang tradisional; h/. Log pon; dan i/. Kapal penyeberangan. Moda transportasi waterway Sungai Tallo termasuk kategori getek/klotok, sesuai Gambar 3, dimana memuat penumpang dan kendaraan, berbeda dengan dengan bus air dan taxi air yang hanya spesifik memuat penumpang.

a

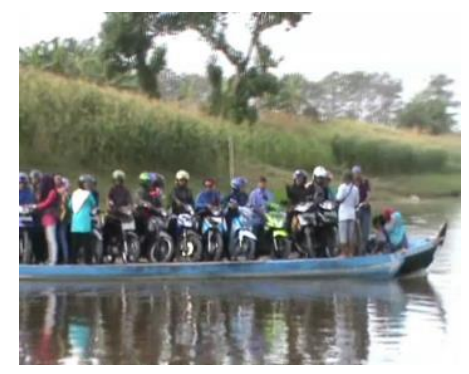

$\mathrm{b}$

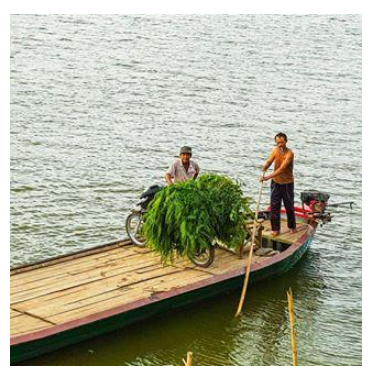

c

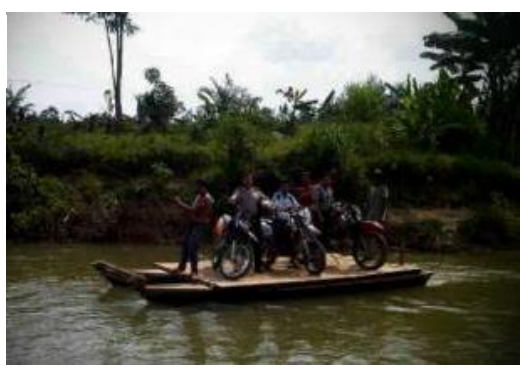

Gambar 3. Aktivitas Moda Waterway di Indonesia, Monohull dan Twin Hull (Katamaran)

\subsection{Dermaga Singgah dan Tempat Tunggu (Terminal) Pelabuhan Sungai dan Danau}

Pelabuhan adalah merupakan suatu lokasi yang terlindung dari gangguan laut/sungai/danau sehingga aktifitas bongkar muat dapat dilaksanakan untuk menjamin keselamatan penumpang dan barang (Kramadibrata, 2002, p. 13). Salah satu sarana/fasilitas pelabuhan terpenting dalam lingkup angkutan sungai/danau adalah dermaga. Dermaga adalah sarana tambatan bagi kapal bersandar untuk bongkar/muat (B/M) barang atau embarkasi/debarkasi penumpang perpindahan intra dan/atau antar moda.

Menurut Peraturan Pemerintah No. 61 Tahun 2009 tentang Kepelabuhan Pasal 1 (19) yang dimaksud dengan terminal fasilitas pelabuhan yang terdiri atas kolam sandar dan tempat kapal bersandar atau tambat, tempat penumpukan, tempat menunggu dan naik turun penumpang, dan/atau tempat bongkar muat barang. 
Sesuai dengan Keputusan Menteri Perhubungan No.53 tahun 2002 tentang Tatanan Kepelabuhanan, klasifikasi pelabuhan ditetapkan dengan memperhatikan: a/. Fasilitas pelabuhan yang terdiri dan fasilitas pokok dan fasilitas penunjang; b/. Volume operasional pelabuhan; dan c/. Peran dan fungsi pelabuhan.

Fasilitas pokok pelabuhan ini meliputi: a/. Perairan tempat labuh termasuk alur pelayaran; b/. Kolam pelabuhan; c/. Fasilitas sandar kapal/dermaga; d/. Penimbangan muatan; e/. Terminal penumpang; f/. Akses penumpang dan barang ke dermaga; g/. Perkantoran untuk kegiatan perkantoran pemerintahan dan pelayanan jasa; h/. Fasilitas penyimpanan bahan bakar (bunker); $\mathrm{i} /$. Instalasi air, listrik dan komunikasi; j/. Akses jalan dan atau rel kereta api; k/. Fasilitas pemadam kebakaran; dan 1/. Tempat tunggu kendaran bermotor sebelum naik ke kapal.

Sedangkan fasilitas penunjang pelabuhan meliputi: a/. Kawasan perkantoran untuk menunjang kelancaran pelayanan jasa kepelabuhanan; b/. Tempat penampungan limbah; c/. Fasilitas usaha yang menunjang kegiatan pelabuhan; dan d/. Area pengembangan pelabuhan.

Secara yuridis, sebuah dermaga harus memenuhi standar pelayanan sandar dan tambat secara layak dan aman bagi penumpang dan barang (PP No. 64 Tahun 2015 perubahan atas PP No. 61 Tahun 2009 tentang Kepelabuhanan). Sedangkan ISM Codes (International Safety Management) menetapkan dasar-dasar keselamatan, dimana keselamatan dimaksudkan adalah jiwa, lingkungan dan harta benda (yakni properti, dimana hal ini dimaksudkan untuk memperoleh profit dan menghindari kerugian, misalnya klaim).

Ada 2 hal pokok yang dapat dinilai dengan mengupayakan keselamatan dermaga, yakni: 1/. Kapal: kondisi aman bagi operasional kapal dan fasilitas pelabuhan; dan 2/. Penumpang dan barang: agar pelayanan terhadap masyarakat lebih terjamin terhadap keselamatan, keamanan dan kenyamanan.

\subsection{Transfer Ipteks ke Mitra}

Ipteks yang akan ditransfer ke mitra berupa pengetahuan pengenalan dan penerapan peralatan/ perangkat keselamatan sarana pelabuhan tempat sandar moda waterway yang sesuai dengan mutu pelayanan sandar dan tambat serta terjamin terhadap keselamatan, keamanan dan kenyamanan bagi penumpang dan barang. Lebih lanjut, pengenalan sarana pelabuhan akan disampaikan pula dalam sosialisasi guna meningkatkan pengetahuan bagi pemilik moda waterway tentang kelengkapan minimal sebuah dermaga beserta perangkat keselamatannya dalam peningkatan mutu pelayanan sandar dan tambat yang layak serta terjamin terhadap keselamatan, keamanan dan kenyamanan bagi penumpang dan muatan.

Adapun perangkat keselamatan sebuah dermaga ini meliputi:

a) Perlunya adanya fender; Fender dapat meredam energi yang ditimbulkan oleh moda transportasi air pada saat akan merapat ke dermaga. 

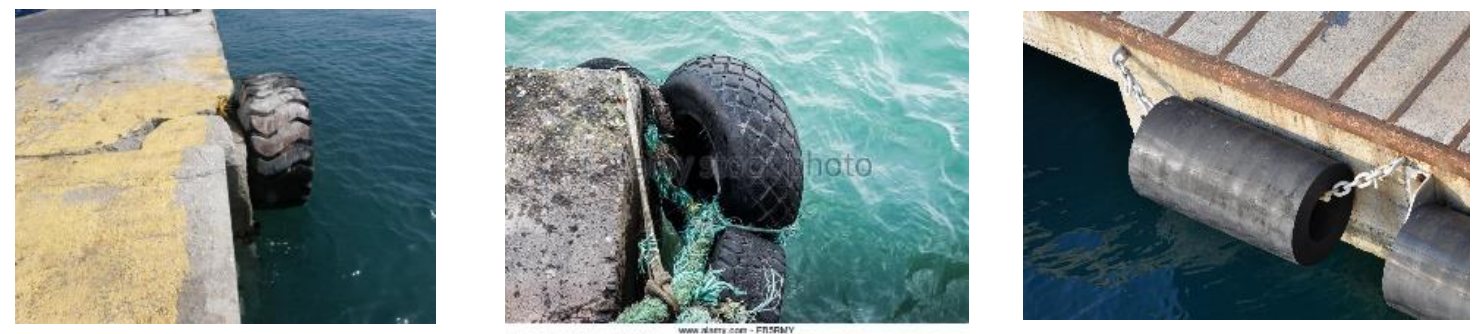

Gambar 4. Contoh Beberapa Fender yang digunakan pada Dermaga

b) Perlunya adanya pelampung penolong, seperti wujud cincin (ring life buoy); Pelampung penolong ini berguna untuk mengapungkan orang yang menggunakannya di atas air dan dapat dimanfaatkan penumpang agar mudah terapung di laut pada saat berlangsung kondisi darurat, sesuai Gambar 5. Ring life buoy ini berbentuk seperti ban mobil dan harus memiliki warna yang mencolok agar mudah dilihat/ditemukan. Pelampung penolong dilempar ke laut apabila ada satu orang penumpang yang jatuh ke laut. Sarana ini rata-rata terbuat dari gabus pejal dan tahan terhadap minyak. Pelampung ini harus mempunyai warna yang mencolok agar mudah dikenali. Pada pelampung dicantumkan huruf balok sesuai dengan nama dermaga atau moda transportasi waterway.
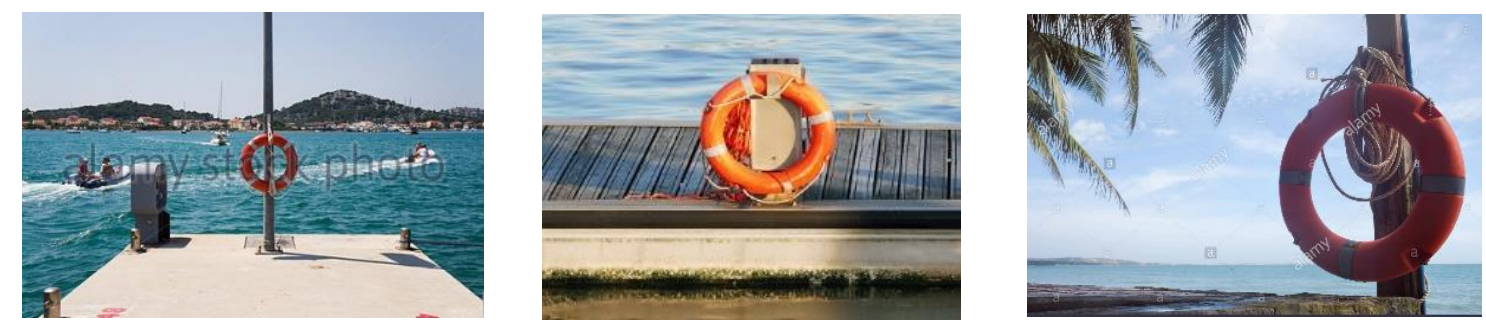

Gambar 5. Contoh Penempatan Ring Life Buoy pada Dermaga

c) Perlunya adanya lampu penerangan di dermaga (hurricane lamp on port); Lampu penerangan di dermaga ini sangat diperlukan pada saat terjadi badai ekstrim. Operator moda waterway akan kesulitan melihat dermaga yang dituju pada saat kondisi hujan disertai badai, terlebih lagi jika dioperasikan pada malam hari. Adapun contoh lampu penerangan di dermaga ditunjukkan pada Gambar 6.
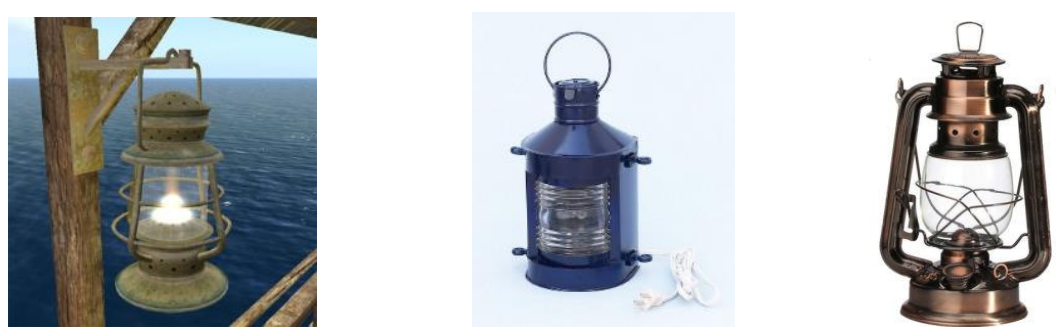

Gambar 6. Contoh Lampu Penerangan di Dermaga 
d) Perlunya adanya lampu navigasi di depan perairan dermaga (navigation lamp on port); Lampu navigasi di depan perairan dermaga sangat dibutuhkan jika lalu lintas moda waterway yang beroperasi mulai cukup banyak. Lampu navigasi ini berfungsi sebagai informasi jalur sisi kanan (starboard side) -yang ditandai dengan lampu hijau- dan sisi kiri (port side) -yang ditandai dengan lampu merah- yang harus dilalui sebuah moda waterway agar tidak terjadi tabrakan antar moda waterway atau perahu.
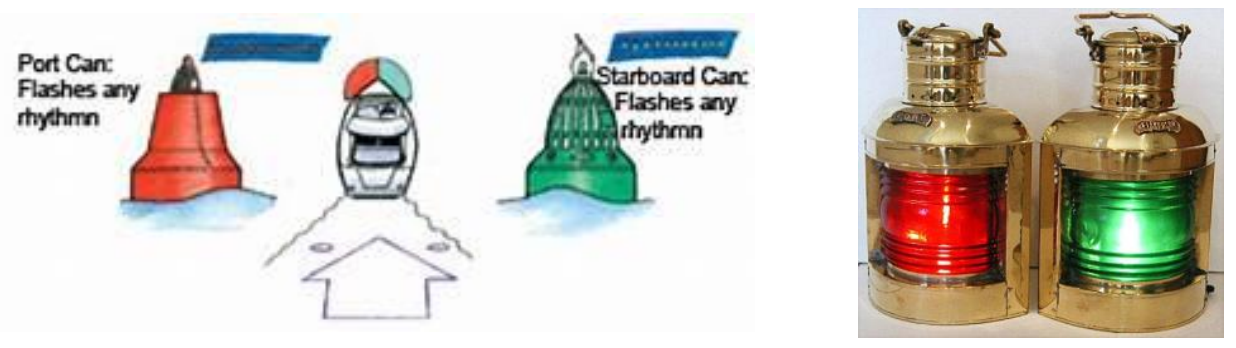

Gambar 7. Contoh Lampu Penerangan di Dermaga pada Dermaga dan Kapal

e) Papan peringatan tentang keselamatan di area dermaga dan sekitarnya pada tempat-tempat strategis; Hal ini sangat dibutuhkan guna menunjang aspek keselamatan jiwa di area dermaga dan sekitarnya dan tempat-tempat strategis perairan. Selain aspek keselamatan penumpang/ jiwa dan barang/properti, papan peringatan juga diarahkan pula pada perlindungan lingkungan perairan. Hal ini sangat penting dilakukan guna menjaga kelestarian lingkungan di area dermaga dan sekitarnya, terlebih lagi Pulau Lakkang juga ditetapkan sebagai kawasan konservasi alam.

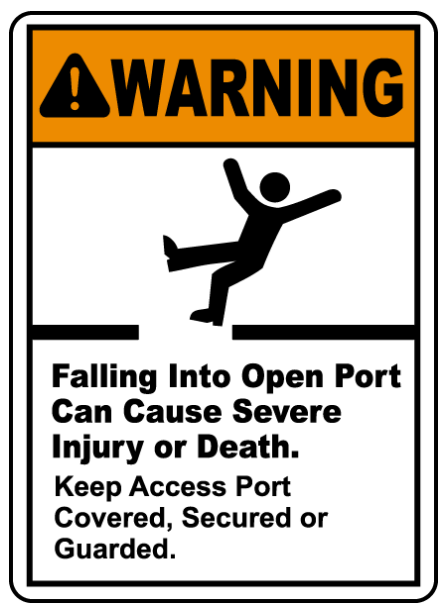

\section{PERHATIAN}

\section{Pentingnya Papan Peringatan tentang Keselamatan di tempat strategis}

Jatuh ke Perairan Terbuka Pelabuhan dapat Menyebabkan Cedera Parah atau Kematian.

Jagalah Akses Pelabuhan tetapTertutup, Aman, atau Terlindungi

Gambar 8. Contoh Papan Peringatan yang Digunakan di Dermaga 

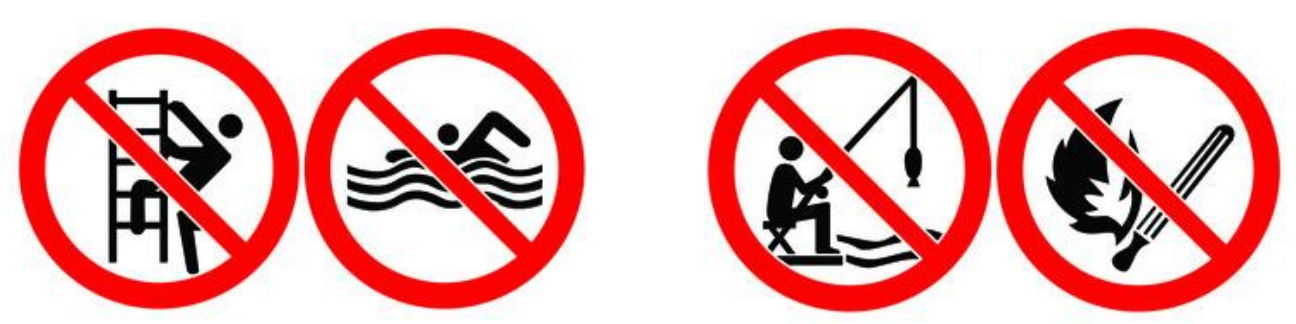

Gambar 9. Contoh Papan Peringatan Tentang Keselamatan dan Menjaga Lingkungan Perairan

f) Perlunya adanya rambu navigasi di depan perairan dermaga (signs of navigation on port); Rambu navigasi sangat dibutuhkan guna kelancaran berlalu lintas sepanjang perairan Sungai Tallo. Hal ini disebabkan karena perairan Sungai Tallo juga digunakan sebagai jalur bagi perahu-perahu penangkap ikan dan petani pohon nipah. Dengan adanya rambu navigasi ini diharapkan pengguna peraian dapat lebih teratur dan menghindari terjadinya kecelakaan yakni tabrakan antar moda di perairan Sungai Tallo.

Contoh rambu navigasi misalnya rambu larangan. Rambu Larangan berbentuk empat persegi panjang. berukuran 100 x $40 \mathrm{~cm}$ warna dasar putih dengan sebuah garis diagonal dan garis tepi warna merah setebal $10 \mathrm{~cm}$, sedang petunjuk berwarna hitam dan angka-angka di dalam rambu berukuran tinggi $60 \mathrm{~cm}$ dan tebal $10 \mathrm{~cm}$. Rambu larangan berbentuk lingkaran berukuran diamater $100 \mathrm{~cm}$. Warna dasar putih dengan sebuah garis diagonal dan garis tepi lingkaran berwarna merah dengan ketebalan $10 \mathrm{~cm}$. Papan tambahan pada rambu larangan berukuran $100 \mathrm{x}$ $40 \mathrm{~cm}$ dengan warna dasar putih dan warna huruf dan/atau angka berwarna hitam. Pada gambar berikut ditunjukkan beberapa rambu larangan yang telah digunakan di Indonesia (AINANSS, 2006; SK Dirjen Hubla, 1993).
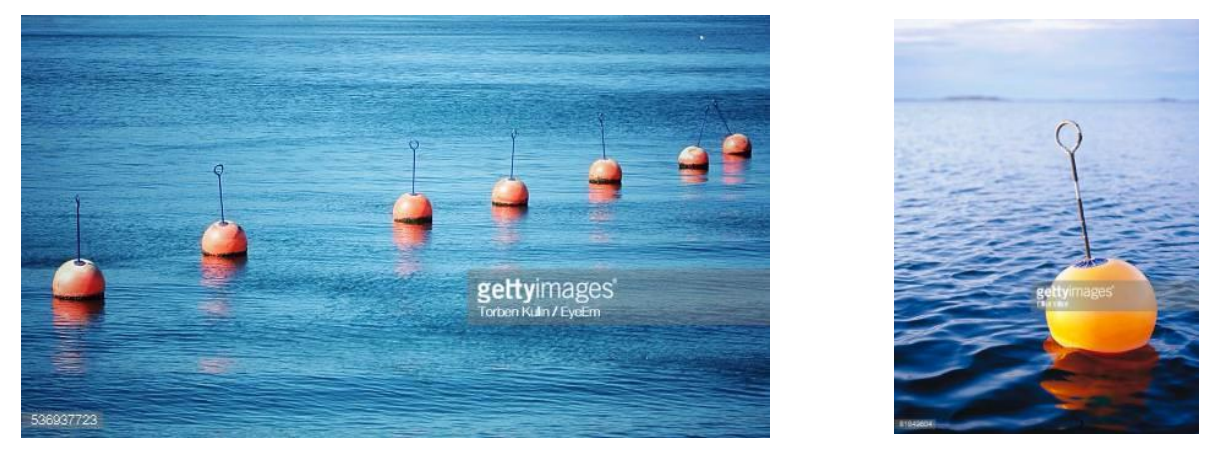

Gambar 10. Contoh Rambu Navigasi pada Alur Pelayaran 


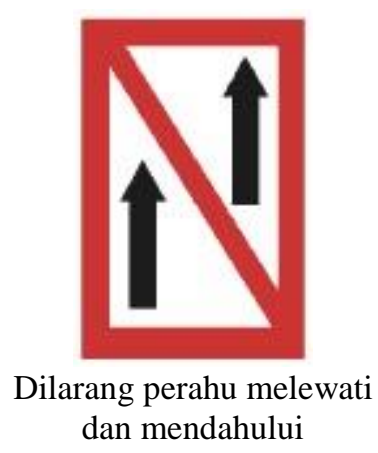

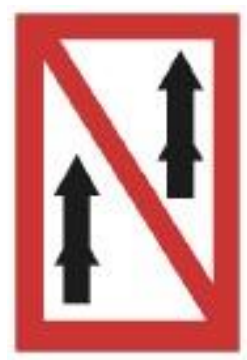

Dilarang melewati bagi kapal yang sedang mendorong kapal lain

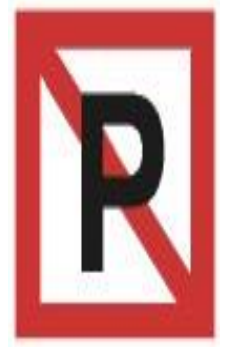

Dilarang bertambat dipinggir jalan air, dimana rambu dipasang

Gambar 11. Contoh Rambu Larangan pada Alur Pelayaran

\section{Metode}

Untuk pemenuhan keselamatan pengoperasian pelabuhan moda waterway Sungai Tallo yang kurang dilengkapi dengan perangkat keselamatan dan peninjauan kelayakan sebuah dermaga dari aspek keselamatan penumpang dan barang yang harus memenuhi standar pelayanan sandar dan tambat secara layak dan aman serta terjamin terhadap keselamatan, keamanan dan kenyamanan bagi penumpang dan barang (PP No. 64 Tahun 2015), maka diperlukan sosialisasi pengenalan dan penerapan penggunaan perangkat keselamatan dan pemenuhan sarana pelabuhan dermaga secara kolektif kepada kelompok pemilik moda waterway Sungai Tallo. Sosialisasi ini untuk peningkatan mutu layanan terhadap penumpang dan muatan moda waterway Sungai Tallo.

Adapun prosedur kerja guna mendukung realisasi pendekatan/solusi yang akan dilakukan adalah: a/. Persiapan internal dilakukan oleh tim yang akan melakukan pengabdian; b/. Pengambilan Data dan Administrasi pada Kecamatan Tallo dan Kelurahan Lakkang serta melakukan wawancara dengan kelompok pemilik moda waterway Sungai Tallo; c/. Pengadaan peralatan keselamatan jiwa di dermaga, balok dan papan kayu; d/. Penyerahan bantuan material papan dan balok kayu sebagai perbaikan dermaga dan perbaikan sarana waterway bagi pemilik moda transportasi waterway guna keselamatan jiwa pengguna dermaga dan penumpang; e/. Pembuatan materi sosialisasi; f/. Fabrikasi perbaikan trestle ke dermaga dan geladak moda waterway oleh kelompok moda waterway; g/. Sosialisasi Kemandirian Kelompok Moda Transportasi Waterway Sungai Tallo Makassar dalam Penerapan Keselamatan Sarana Pelabuhan; h/. Seminar hasil, publikasi dan pelaporan. Seluruh tahapan kegiatan ini dilakukan bersama dengan mitra kerja. Sosialisasi pengenalan perangkat keselamatan sarana pelabuhan moda waterway Sungai Tallo Makassar diterima oleh mitra kerja.

Metode yang digunakan adalah pendekatan partisipatif aktif dengan pelibatan mitra kerja dalam sosialisasi perangkat keselamatan sarana pelabuhan secara mandiri sesuai dengan mutu pelayanan sandar dan tambat secara layak dan aman bagi penumpang dan kendaraan roda dua. Hal ini dimaksudkan agar mitra kerja merasa memiliki tanggung jawab pelayanan terhadap penumpang dan fasilitas yang ada di area dermaga labuh, sehingga dalam proses maintenancel pemeliharaan sarana pelabuhan akan lebih mudah dilakukan. Kesulitan-kesulitan yang dihadapi oleh mitra kerja dalam sosialisasi ini adalah perubahan cara berfikir pemilik moda waterway dalam pemenuhan perangkat keselamatan sarana pelabuhan secara mandiri. 
Untuk mengetahui tingkat pemahaman warga terhadap peralatan keselamatan ini dalam aktifitas kesehariannya oleh kelompok moda waterway, tujuh hari setelah sosialisasi dan proses penyerahan bantuan perangkat keselamatan moda waterway dilakukan pemantauan. Pemantauan ini dimaksudkan untuk melihat perkembangan dan pendapat warga pengguna moda waterway serta kemungkinan untuk menerapkan bantuan serupa pada kelompok moda waterway lainnya. Respon positif diberikan oleh penumpang pengguna moda waterway. Mereka berharap bahwa kegiatan serupa yang memberi nuansa pengetahuan baru bagi kelompok moda waterway dan dapat dilakukan di masa-masa yang akan datang.

\section{Hasil dan Diskusi}

Aktifitas pengabdian dilaksanakan di Kelurahan Lakkang Kecamatan Tallo Kota Makassar mulai dari rentang tanggal 23 Oktober hingga 25 November 2017. Aktivitas pengenalan perangkat keselamatan sarana pelabuhan moda waterway Sungai Tallo Makassar diselenggarakan bagi pemilik/operator moda waterway dan warga Kelurahan Lakkang yang dilakukan selama 1 hari yakni tanggal 12 November 2017. Sosialisasi ini melibatkan kelompok moda waterway Sungai Tallo yang beranggotakan 10 orang yang sekaligus berperan sebagai mitra kerja dan diikuti pula oleh perwakilan warga Kelurahan Lakkang. Profesi utama anggota mitra kerja ini adalah nelayan dan petani. Kelompok moda transportasi moda waterway Sungai Tallo ini melakukan pengadaan moda waterway secara mandiri sebagai mata pencarian alternatif setelah mereka melakukan aktifitas nelayan atau bertani.

Pelaksanaan kegiatan sosialisasi ini dilakukan dengan rangkaian tahapan berikut:

a) Persiapan internal dilakukan oleh tim sosialisasi; Persiapan ini meliputi persiapan administrasi dan persiapan personal tim yang melakukan pengambilan data administrasi ke pemerintah setempat dan wawancara dengan warga Pulau Lakkang selaku pengguna moda waterway.

b) Pengambilan data dan perijinan administrasi pada Kantor Kecamatan Tallo dan Kelurahan Lakkang serta melakukan wawancara dengan kelompok pemilik moda waterway Sungai Tallo; Setelah ijin kegiatan diperoleh dari Pemerintah Kecamatan Tallo dan Kelurahan Lakkang, selanjutnya dilakukan wawancara dengan kelompok pemilik moda waterway Sungai Tallo. Tim menyampaikan maksud dan tujuan kegiatan sosialisasi serta mengidentifikasi permasalahan yang dialami oleh pemilik/operator moda waterway yang seluruhnya bermukim di Pulau Lakkang. Hasil interview dengan kelompok moda waterway diperoleh identifikasi permasalahan dan data eksisting sesuai Gambar 12 yaitu:

- Pemilik moda waterway belum memahami peraturan keselamatan sarana pelabuhan moda waterway yang sesuai dengan mutu pelayanan sandar dan tambat secara layak dan aman bagi penumpang dan barang, sehingga penyelenggaraan sosialisasi sangat penting untuk memperoleh pengetahuan pentingnya pemenuhan kebutuhan perangkat keselamatan sarana pelabuhan tempat sandar moda waterway;

- Anggota kelompok moda waterway menyampaikan keluh kesahnya bahwa sebagian dermaga yang telah dibangun mulai mengalami penurunan fungsi konstruksi/kerusakan di beberapa bagian. Seperti pada Dermaga 3 Lakkang, kondisi dermaga masih sangat baik, namun jembatan penghubung (trestle) menuju dermaga yang mengalami kerusakan, yakni elemen konstruksi balok pembujur trestle ke dermaga dan sebagian papan trestle. Hal ini disebabkan karena kualitas kayu yang kurang baik/bervariasi jenis kayunya. 
Mereka telah berinisiatif memperbaiki trestle dengan mengganti elemen konstruksi balok pembujur trestle yang telah lapuk dengan material bambu. Inisiatif lainnya juga dilakukan dengan mengganti papan geladak trestle yang rusak dengan papan sisa-sisa bangunan. Saat ini, kondisi bambu dan papan geladak yang digantipun telah mengalami kerusakan, sehingga pemilik moda waterway merasa khawatir atas keselamatan, keamanan dan kenyamanan penumpang maupun turis yang berwisata ke Pulau Lakkang akan mengalami kecelakaan akibat kondisi trestle tersebut;

a

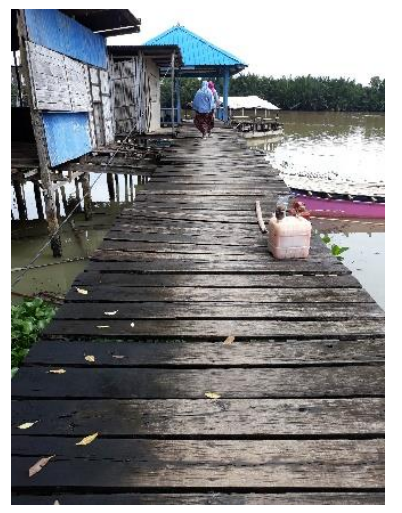

$\mathrm{b}$

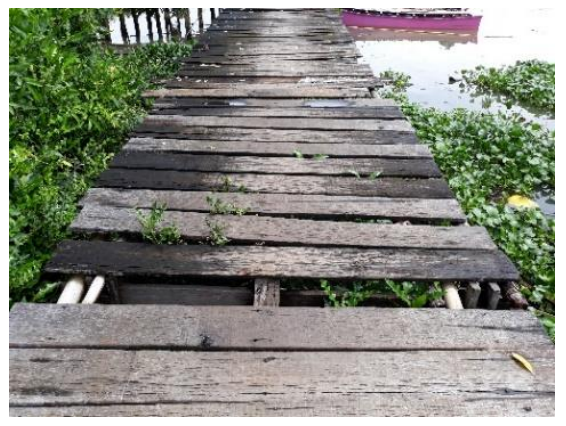

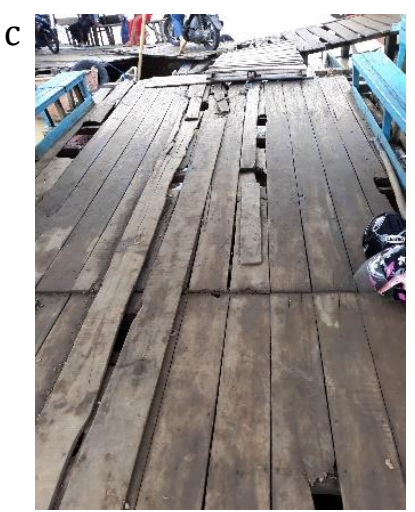

Gambar 12. Kondisi Kerusakan Sarana Pelabuhan Trestle dan Geladak Moda Waterway Sumber: Dokumentasi survey (2017)

- Anggota kelompok moda waterway juga merasa kesulitan untuk memperbaiki kerusakan papan geladak moda waterway-nya yang lapuk dan pecah-pecah. Mereka khawatir akan memakan korban penumpang yang sedang dimuat, khususnya pada saat hari libur dimana jumlah wisatawan yang meningkat. Anggota kelompok moda waterway sadar bahwa kondisi ini sangat membahayakan keselamatan para penumpang saat menapakkan kakinya atau menempatkan kendaraan roda duanya di geladak berlobang yang menyebabkan terjerembab/tercebur ke sungai.

c) Pengadaan peralatan keselamatan jiwa di dermaga, balok dan papan kayu; Atas dasar hasil pengamatan lapangan dan diskusi antara tim peneliti dengan anggota kelompok moda waterway, selanjutnya pada tanggal 4 s.d. 5 November 2017 dilakukan pengadaan peralatan pelampung penolong (ring of life), balok kayu sebagai pengganti elemen konstruksi balok pembujur trestle, dan papan geladak moda waterway, sesuai Gambar 13;

d) Penyerahan bantuan balok kayu untuk perbaikan trestle ke dermaga dan material papan kayu untuk perbaikan sarana waterway bagi pemilik moda waterway guna keselamatan pengguna dermaga dan penumpang; Penyerahan bantuan balok kayu dan papan geladak dilakukan pada tanggal 5 November 2017. Balok kayu digunakan untuk perbaikan dermaga 3, dimana balok kayu pembujur trestle telah rapuh. Sedangkan papan kayu sebagai material papan geladak diberikan kepada 3 pemilik angkutan moda yang geladak moda waterway-nya mengalami kerusakan. Adapun 3 pemilik moda tersebut adalah Bapak Dg. Japri, Dg. Azis dan Dg. Nasrul. Adapun kondisi ketiga moda waterway yang akan memperoleh bantuan seperti ditunjukkan pada Gambar 14. Bantuan balok dan papan kayu ini bertujuan sebagai trigger/ pemicu bagi pemilik moda untuk lebih aktif dalam menjaga keselamatan pelayaran transportasi moda waterway-nya. Kami hanya menyediakan material induk, sedangkan material pendukung lainnya seperti paku, mur dan baut, dan peralatan serta tenaga kerja bersumber dari masyarakat. 
a

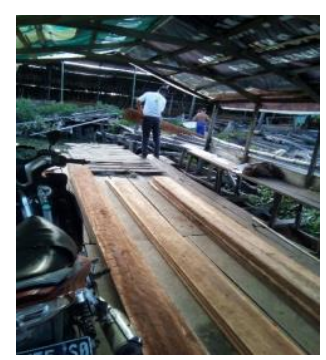

$\mathrm{b}$

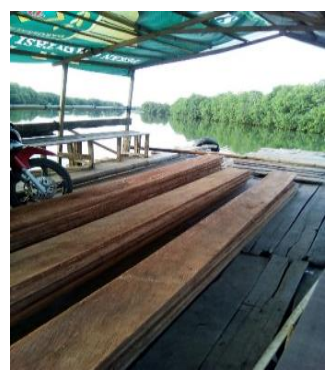

c

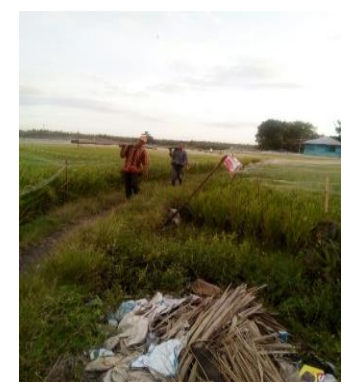

$\mathrm{d}$

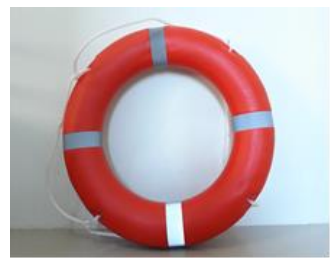

$\mathrm{e}$

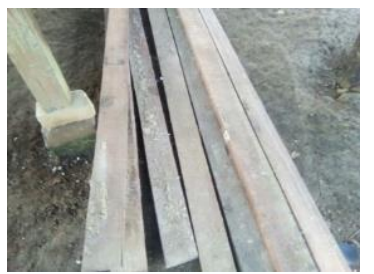

Gambar 13. Pengadaan dan Penyerahan Perangkat Keselamatan, Balok dan Papan Kayu Sumber: Dokumentasi (2017)

a

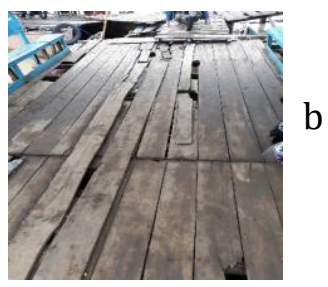

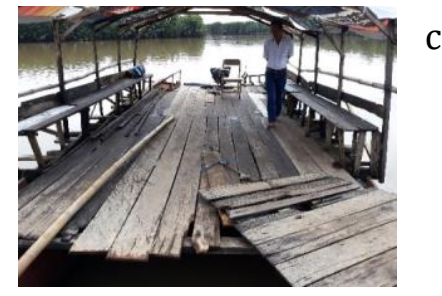

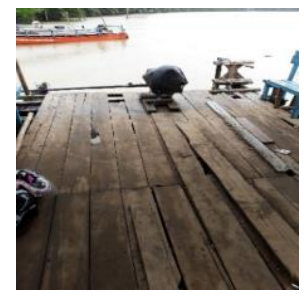

Gambar 14. Kondisi Ketiga Geladak Moda Waterway yang Rusak

Sumber: Dokumentasi survey (2017)

e) Pembuatan materi sosialisasi; Materi sosialisasi dibuat dengan mengacu pada aturan dan referensi terkait dengan perangkat keselamatan sarana pelabuhan, dengan memperhatikan kondisi pelabuhan eksisting.

f) Fabrikasi perbaikan trestle ke dermaga dan geladak moda waterway oleh kelompok moda waterway; Konstruksi trestle yang diperbaiki adalah terletak pada dermaga 3 Lakkang, sesuai Gambar 15. Dermaga ini merupakan bantuan dari Dinas Perikanan dan Kelautan yang dibangun pada tahun 2013. Kondisi dermaga masih cukup baik, namun kondisi trestle-nya yang sudah rusak, yakni balok pembujur yang sudah rapuh. Namun kondisi ini telah diperbaiki oleh warga dengan mengganti balok pembujur trestle dengan bambu. Bambupun tidak bertahan lama karena pecah dan akhirnya lapuk. 
a

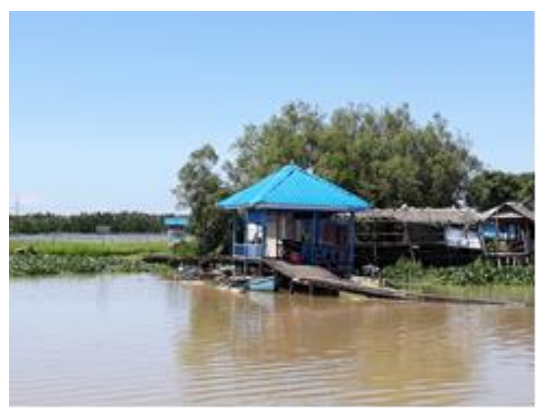

b

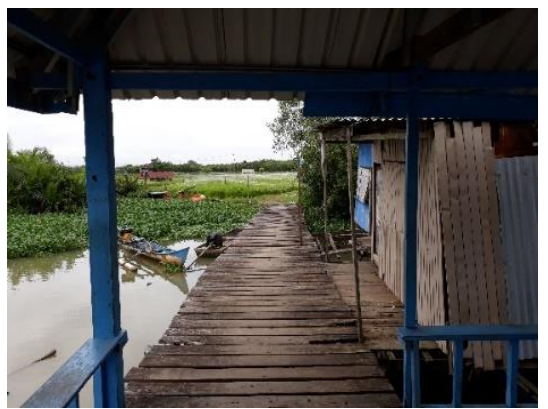

Gambar 15. Lokasi Dermaga 3 dan Kondisi Trestle yang Akan Difabrikasi Sumber: Dokumentasi survey (2017)

Aktifitas fabrikasi trestle dilakukan pada tanggal 11 November 2017 bertempat di atas trestle yang mengalami kerusakan dan dilakukan secara gotong royong oleh pemilik moda waterway dan warga, sesuai Gambar 16.

Finishing pekerjaan trestle ini terdiri atas pemasangan elemen konstruksi pembujur trestle dengan ukuran balok $5 \mathrm{~cm} \times 10 \mathrm{~cm} \times 4 \mathrm{~m}$ dan pemasangan papan trestle dengan ukuran papan geladak 5cmx25cmx6m, seperti ditunjukkan pada Gambar 17.

Perbaikan papan geladak moda waterway dilakukan oleh masih-masing pemilik moda waterway dengan rentang waktu pengerjaan pada tanggal 13 s.d. 25 November 2017 sesuai kelonggarran waktu dari masing-masing pemilik moda waterway. Jumlah perbaikan untuk papan geladak moda waterway dari alokasi dana yang ada hanya dapat digunakan untuk membeli material papan kayu untuk 3 moda waterway dari total jumlah 6 moda waterway yang beroperasi dengan trayek Kera-kera - Lakkang, seperti ditunjukkan pada Gambar 18.

g) Sosialisasi Kemandirian Kelompok Moda Transportasi Waterway Sungai Tallo Makassar dalam Penerapan Keselamatan Sarana Pelabuhan; Sosialisasi ini dilakukan pada hari Minggu tanggal 12 November 2017 bertempat di permukiman warga yakni Bapak Japar, ketua kelompok moda waterway. Sosialisasi dihadiri oleh peserta yakni warga Kelurahan Lakkang sebanyak 35 orang. Warga sangat antusias mengikuti sosialisasi karena hal ini menyangkut keselamatan jiwa warga yang menggunakan sarana moda waterway sehari-hari. Mereka baru sadar bahwa pemenuhan perangkat keselamatan pelayaran dengan moda waterway ini akan menarik dan meningkatkan kunjungan wisatawan baik turis domestik maupun manca negara/ asing.

a

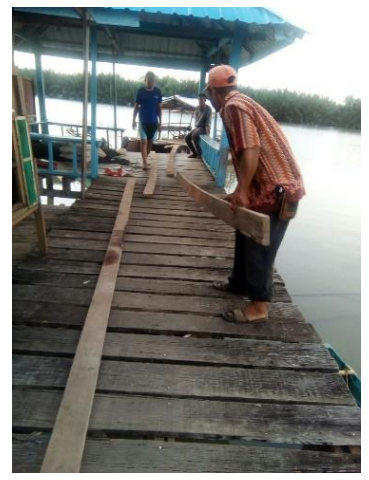

b

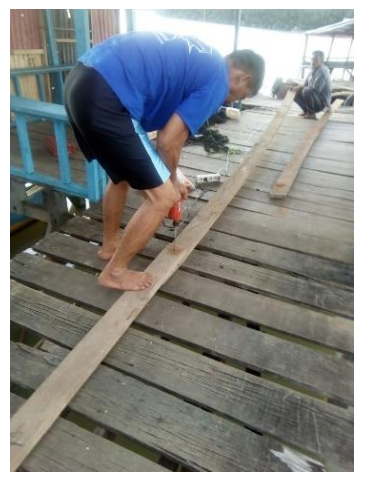

c

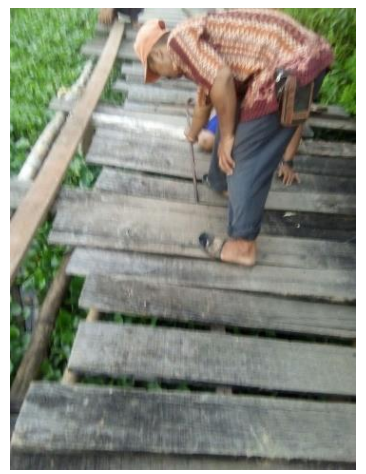


d

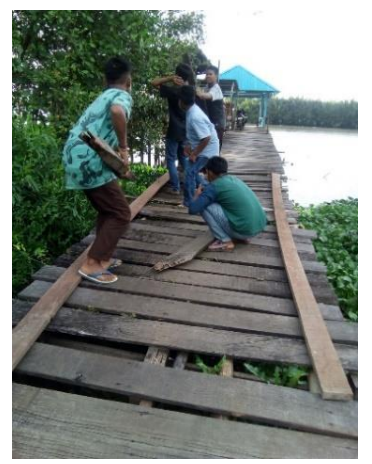

e

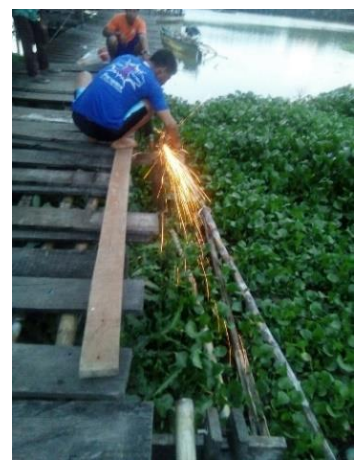

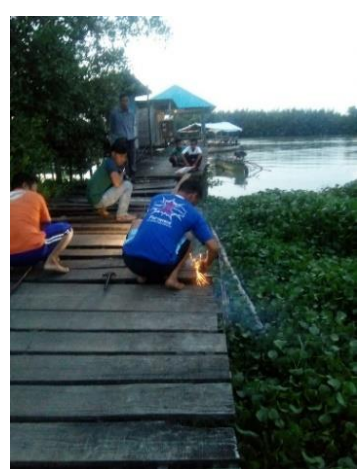

Gambar 16. Proses Fabrikasi Perbaikan Trestle Dermaga 3 Lakkang Sumber: Dokumentasi (2017)

a

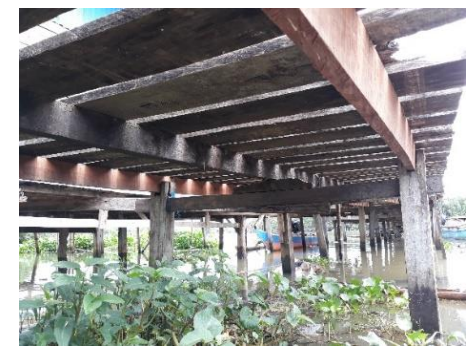

b

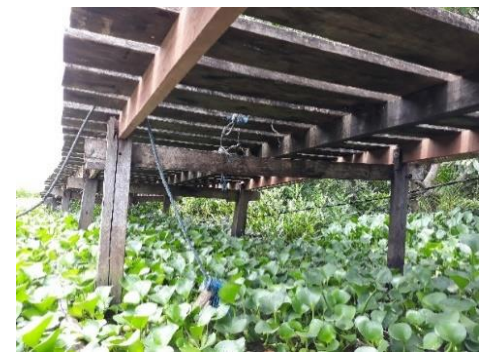

C

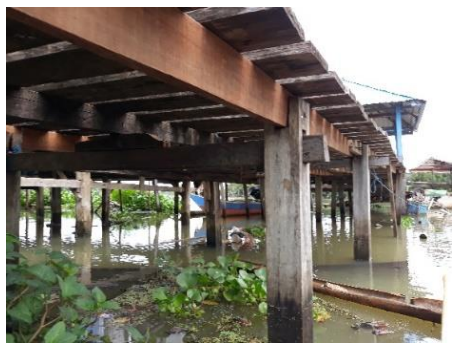

d

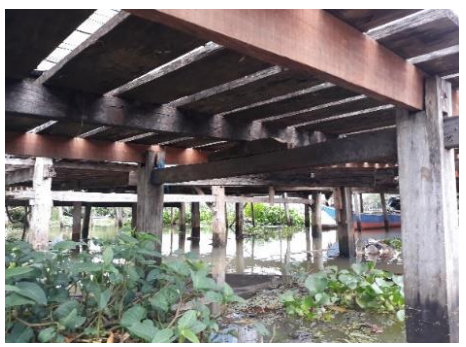

Gambar 17. Hasil Perbaikan Balok Pembujur Trestle yang Rusak Sumber: Dokumentasi (2017)

a

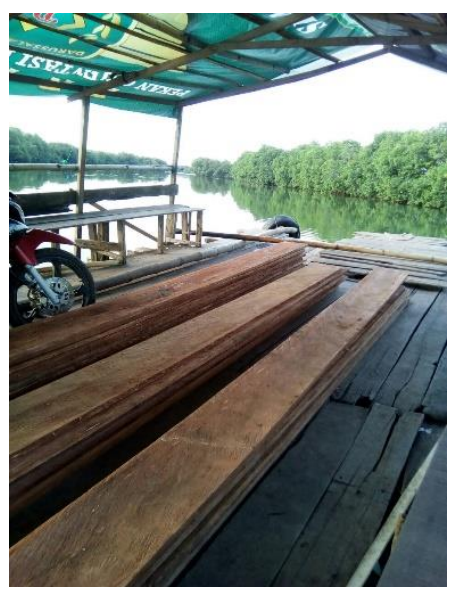

b

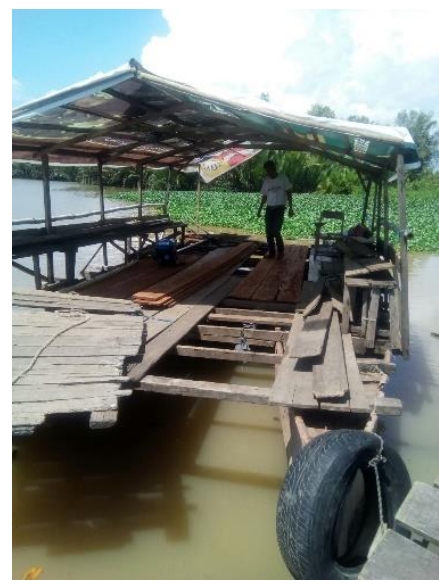

C

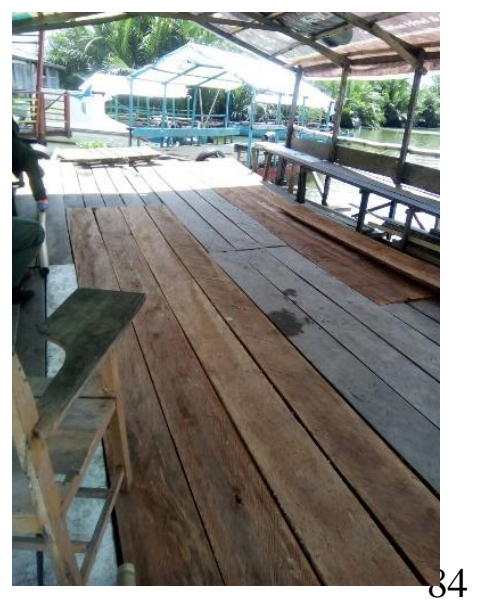


$\mathrm{d}$

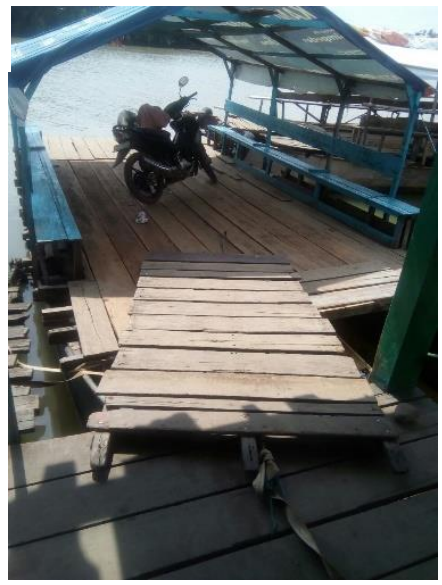

e

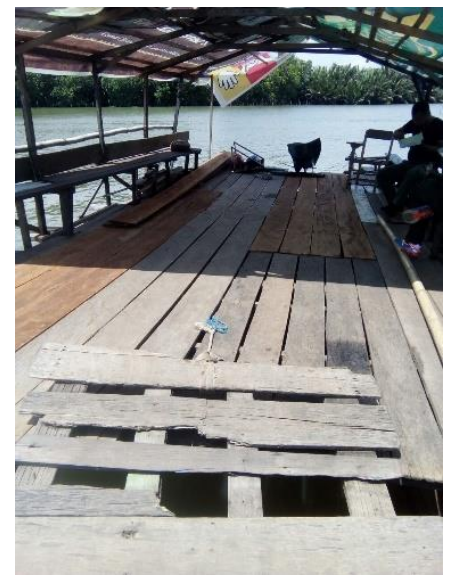

$\mathrm{f}$

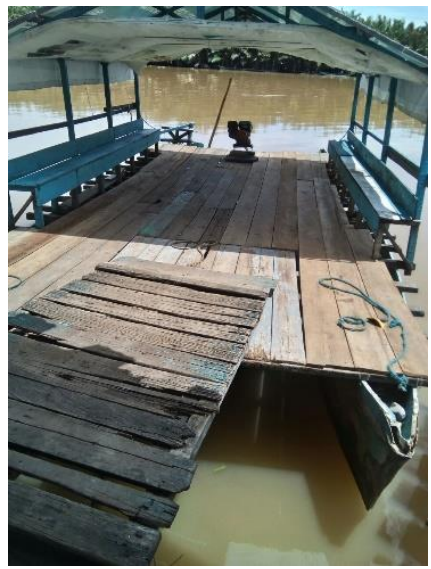

Gambar 18. Fabrikasi Perbaikan Papan Geladak Ketiga Moda Waterway

Sumber: Dokumentasi (2017)

a

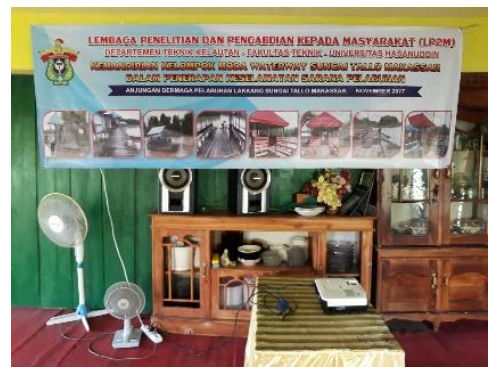

b

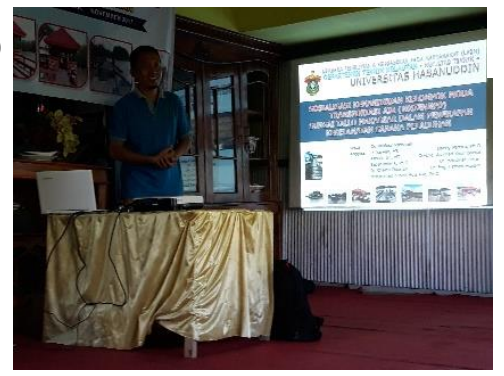

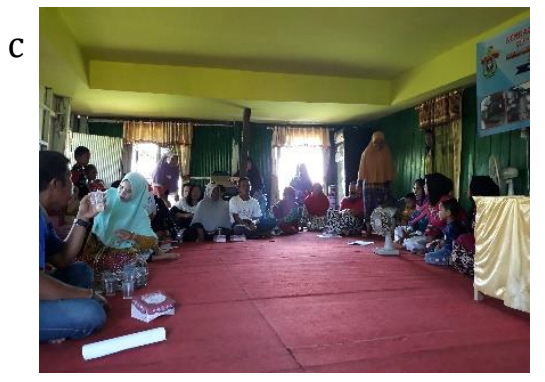

Gambar 19. Pelasanaan Sosialisasi

Sumber: Dokumentasi (2017)

h) Seminar hasil, publikasi dan pelaporan; Seminar hasil dan pelaporan mengikuti jadwal yang ditetapkan oleh LP2M Unhas, serta publikasi dimuat pada jurnal.

Dengan berakhirnya proses sosialisasi dan perbaikan jembatan penghubung (trestle) dan geladak moda waterway kepada kelompok moda waterway ini diharapkan dapat menambah kenyamanan dan rasa aman penumpang lokal dan pengunjung wisata Lakkang baik turis domestik maupun mancanegara dalam pelayaran dan proses bongkar dan muat waterway di dermaga 3 Lakkang. Respon positif diberikan oleh penumpang pengguna moda waterway. Mereka berharap bahwa kegiatan serupa yang memberi nuansa pengetahuan baru bagi kelompok moda waterway sebagai operator khususnya dan kepada khalayak warga Kelurahan Lakkang umumnya, dapat dilakukan di masa-masa mendatang. 
Tujuh hari setelah kegiatan sosialisasi, tepatnya tanggal 19 November 2017 dilakukan pemantauan untuk mengevaluasi perkembangan dan pendapat warga pengguna moda waterway. Hasil pemantauan diperoleh bahwa kelompok moda waterway telah melakukan aktifitas seperti sedia kala dengan memanfaatkan konstruksi dermaga 3 dan jembatan penghubung (trestle) yang telah diperbaiki. Kelompok moda waterway ini menghimbau adanya bantuan serupa bagi kelompok moda waterway lain di Kelurahan Lakkang Kecamatan Tallo. Lebih lanjut, pemantauan juga dilakukan pada kelompok moda waterway lain di wilayah Kelurahan Lakkang. Hal ini dimaksudkan untuk melihat perkembangan dan pendapat warga serta kemungkinan untuk menerapkan bantuan serupa pada kelompok moda waterway lain. Respon positif diberikan oleh kelompok moda waterway Lakkang-Kera-kera maupun kelompok moda waterway lain, yakni rute Lakkang-Tol Ir. Sutami.

\section{Kesimpulan}

Dengan berakhirnya proses sosialisasi dan perbaikan jembatan penghubung (trestle) dan geladak moda waterway kepada kelompok moda waterway ini diharapkan dapat meningkatkan mutu layanan, yakni keselamatan, keamanan dan kenyamanan penumpang lokal dan pengunjung wisata Lakkang baik turis domestik maupun mancanegara dalam pelayaran dan proses bongkar dan muat waterway di dermaga 3 Lakkang. Respon positif diberikan oleh penumpang pengguna moda waterway. Mereka berharap bahwa kegiatan serupa yang memberi nuansa pengetahuan baru bagi kelompok moda waterway sebagai operator khususnya dan kepada khalayak warga Kelurahan Lakkang umumnya, dapat dilakukan di masa-masa mendatang.

\section{Ucapan Terima Kasih}

Penulis mengucapkan terima kasih kepada Lembaga Penelitian dan Pengabdian Masyarakat (LP2M) Universitas Hasanuddin yang telah mendukung dana untuk kegiatan sosialisasi ini dalam skema Program Pengabdian pada Masyarakat Unhas (PPMU) - Hibah Ipteks bagi Masyarakat (IbM) tahun 2017. 


\section{Daftar Pustaka}

Kramadibrata, S. (2002). Perencanaan Pelabuhan, Bandung: Penerbit 1TB.

Triatmodjo, B. (2008). Pelabuhan, Yogyakarta: Beta Offset.

Peraturan Pemerintah Nomor 64 Tahun 2015 tentang perubahan atas Peraturan Pemerintah 61 Tahun 2009 tentang Kepelabuhanan Pasal 63 poin 4.

Peraturan Menteri Perhubungan Republik Indonesia No. PM 51 Tahun 2015 tentang Penyelenggaraan Pelabuhan Laut, Pasal 21 poin 4.

Peraturan Pemerintah No. 22 Tahun 2011 tentang Angkutan di Perairan.

Keputusan Menteri No. 73 Tahun 2004 tentang Penyelenggaraan Angkutan Sungai.

Peraturan Pemerintah No. 82 Tahun 1999 tentang Penyelenggaraan Angkutan Sungai Pasal 14.

Undang-Undang No. 17 Tahun 2008 tentang Pelayaran Pasal 116 Ayat 1 Perlindungan Lingkungan Maritim.

International Maritime Organization (IMO) Tahun 1999.

Keputusan Menteri Perhubungan No.53 tahun 2002 tentang Tatanan Kepelabuhanan.

ISM (International Safety Management) Codes. (2002)

Association of Inland Navigation Autorities, Navigation Signs and Symbols, 2006. An Industry Standard for UK Inland Waterways, London.

Surat Keputusan Direktur Jenderal Perhubungan Darat No: HK 206/1/20/DPRD/93 tentang Perambuan di Perairan Daratan dan Penyeberangan. 